\title{
Perencanaan Instalasi Pengolahan Air Limbah Desa Siulak Gedang Kecamatan Siulak Kabupaten Kerinci
}

\author{
Fajar Arsyadani $^{1}$, Monik Kasman ${ }^{2 *}$, Ira Galih Prabasari ${ }^{3}$ \\ ${ }^{1,2,3}$ Program Studi Teknik Lingkungan, Fakultas Teknik, Universitas Batanghari \\ Jalan Slamet Riyadi, Kota Jambi \\ e-mail: monik.kasman@unbari.ac.id
}

\begin{abstract}
Siulak Gedang, a village lies on Siulak District, Kabupaten Kerinci which has old common treatment system for its domestic wastewater system. Black water is treated in impermeable septic tank so that the wastewater directly seeps into the ground is discharged into public drains. Meanwhile, grey water is channeled directly into the public drainage. Thus, domestic wastewater treatment is needed for Siulak Gedang Village to avoid water pollution due to the direct discharge of wastewater. The design for domestic wastewater system is divided into 2 parts of wastewater treatment plant (Instalasi Pengolahan Air Limbah $=$ IPAL) that operates simultaneously using anaerobic baffled reactor $(A B R)$ which combined with constructed wetland. Based on the calculation, the peak discharge of population services is $2198,4 \mathrm{~m}^{3} / \mathrm{day}$. The IPAL consists of a grease trap as a separator for oil and grease, a collection tank, a distribution tank, an ABR tank as the main processing unit for wastewater and further processing with a constructed wetland in sanitary pool.
\end{abstract}

Keywords: Anaerobic Baffled Reactor; Domestic wastewater; IPAL

\section{Pendahuluan}

Pertumbuhan penduduk yang begitu cepat di Desa Siulak Gedang, Kabupaten Kerinci diduga berdampak pada daya dukung lingkungan. Pengolahan air limbah contohnya, selama ini masyarakat mengolah limbah domestik blackwater ke tangki septik yang tak kedap sehingga air limbah langsung meresap ke tanah atau dibuang ke saluran umum. Sedangkan, greywater langsung disalurkan ke saluran drainase.

Sistem penyaluran greywater yang tercampur dengan saluran drainase umum ini bertentangan dengan Peraturan Menteri Pekerjaan Umum No. 12 Tahun 2014 yang menetapkan sistem terpisah antara jaringan drainase dengan pengumpul air limbah. Oleh karena itu diperlukan suatu perencanaan pengolahan air limbah domestik, terutama greywater yang terpusat untuk melayani masyarakat di Desa Siulak Gedang. Dalam rekayasa ini, air limbah greywater direncanakan diolah menggunakan sistem Anaerobic Baffled Reactor dengan alternatif kombinasi pengolahan menggunakan constructed wetland berupa kolam sanitia.

\section{Metode Penelitian}

\subsection{Data Primer}

Data primer berupa gambaran umum Desa Siulak Gedang, Kecamatan Siulak Kabupaten Kerinci, data jumlah penghuni dan lahan yang akan dijadikan lokasi IPAL.

\subsection{Data Sekunder}

Data sekunder terdiri atas:

1. Baku Mutu sesuai dengan (PERMEN LHK No.68 Tahun 2016);

2. Peta Topografi, Tataguna lahan dari BAPPEDA;

3. debit perhitungan air bersih berdasarkan SNI.

\subsection{Perencanaan}

Perencanaan meliputi:

1. Perhitungan debit air limbah yang dihasilkan penduduk berdasarkan SNI;
2. Penetapan dan membandingkan dengan baku mutu air limbah yang berlaku;

3. Penetapan unit pengolahan dan kriteria desain sesuai dengan Ditjen Cipta Karya 1996,dan SNI-037065-2005 Kebutuhan air menurut tipe bangunan;

4. Perhitungan unit-unit IPAL yang digunakan sebagai pengolahan air limbah domestik; dan pengolahan kombinasi kolam sanitia;

5. Gambar desain unit IPAL.

\subsection{Rumus Perhitungan Unit-Unit IPAL yang Digunakan}

1. Perhitungan proyeksi penduduk selama 10 tahun ke depan untuk mendapatkan kuantitas air limbah yang dihasilkan. Aritmatik

$$
\begin{aligned}
& P n=P 0+K a(T n-T 0) \\
& K a=\frac{P 2-P 1}{T 2-T 1} \\
& \text { Geometrik } \\
& P n=P 0(1+r)^{n} \\
& \text { Eksponensial } \\
& P_{t}=P_{o} e^{r t} \\
& r=\frac{1}{t} \ln \left(\frac{P_{t}}{P_{o}}\right)
\end{aligned}
$$

2. Perhitungan fluktasi air buangan, perlu memperhatikan hal berikut sebagai tujuan perencanaan pengolahan air buangan:
a. Luas daerah;
b. Jumlah penduduk;
c. Q Domestik;.
$\mathrm{Q}_{\text {average }}=\mathrm{Q}_{\text {Domestik }}$
Faktor puncak
fpeak $=\left(18+\mathrm{p}^{0.5}\right) /\left(4+\mathrm{p}^{0.5}\right)$
$\mathrm{Q}_{\text {peak }}=\mathrm{Q}_{\text {average }} \mathrm{X}$ fpeak
$\mathrm{Q}_{\text {maksimum }}=\mathrm{Q}_{\text {ave }} \mathrm{X} 1,25$

(faktor debit harian maksimum 1,1 - 1,25)

$\mathrm{Q}_{\text {minimum }}=1 / 5 \times\left(\frac{P}{1000}\right)^{0.8} \times Q_{\text {average }}$

3. Perencanaan unit-unit IPAL anatara lain yaitu: a. Unit grease trap 
Grease trap memliki minimal dua kompartemen. Kompartemen pertama memiliki waktu detensi minimal 7 menit, sedangkan kompartemen kedua memiliki waktu detensi minimal 5 menit (Water, 2011). Grease trap perlu dilakukan pembersihan minyak dan lemak secara berkala untuk menghindari penyumbatan.

b. Unit Bak Pengumpul

Volume $=Q_{\text {peak }} \times \mathrm{T}_{\mathrm{d}}$

Asurface $($ As $)=\frac{V}{\hbar}$

Panjang $=$ Lebar $=\sqrt{A_{S}}$

Cek $\mathrm{T}_{\mathrm{d}}=\frac{V}{Q_{\text {park }}}$

$\mathrm{H}$ air saat $\mathrm{Q}_{\text {ave }}=Q_{\text {ave }} x \frac{T d}{A}$

$\mathrm{H}$ air saat $\mathrm{Q}_{\min }=Q_{\min } x \frac{{ }_{\mathrm{Td}}}{\mathrm{A}}$

$\mathrm{H}$ air saat $\mathrm{Q}_{\text {peak }}=Q_{\text {peak }} x \frac{T d}{A}$

c. Bar Screen

Bar Screen digunakan untuk menyaring air limbah dari pipa sewer sebelum masuk ke bak pengumpul.

Lebar total $=($ jarak antar batang $\times \mathrm{n})+$ (lebar batang $\mathrm{x}(\mathrm{n}-1)$ )

d. Pompa

A pipa $=\frac{Q \text { peak }}{\mathrm{V}}$

diameter discharge pada pompa

$\mathrm{D}=\sqrt{\frac{4 \times \mathrm{A}}{2,14}}$

Apipa cek $=\frac{1}{4} \times \pi \times D^{2}$

kecepatan aliran pompa $\mathrm{v} \operatorname{cek}=\frac{Q}{A}$

Head Mayor $h f$ discharge

$=\left[\frac{\mathrm{Q}}{0,2785 \times \mathrm{L} \times \mathrm{D}^{2}}\right]^{1,85} \times 0,5$

Head Minor $h f=n\left[k_{2 \mathrm{~g}}^{\frac{v^{2}}{2}}\right]$

Hf kecepatan $=\frac{\mathrm{V}^{2}}{2 \mathrm{~g}}=\frac{1^{2}}{2 \times 9,81}=0,05 \mathrm{~m}$

Perhitungan Head Total Pompa

$\mathrm{H}=\mathrm{Hs}+$ Hmayor + Hminor + Hf Kecepatan +

$\mathrm{H}$ sisa tekan

e. Perhitungan ABR (Anaerobic Baffled Reactor)

Efisiensi removal $(\%)=\frac{(a-b)}{a} \times 100 \%(26)$

Organic Loading Rate (OLR)

OLR (kg COD $/ \mathrm{m}^{3}$.hari) $=\frac{\text { GQave . . Sol) }}{\text { Volume ABR }}$

Hydraulic Retention Time (HRT)

HRT $($ jam $)=\frac{\text { Volume raktor }}{Q \text { ave }}$

$\mathrm{V}$-up $(\mathrm{m} / \mathrm{jam})=\frac{\text { Qave }}{\text { As Kompartemen }}$

f. Kolam Sanitia

Dasar dalam pembuatan kolam sanitia ini sesuai dengan SNI-2398-2017 tentang tata cara perencanaan tangki septik dengan pengolahan lanjutan maka direncanakan, waktu detensi (td) 1-1,5 hari.

\section{Hasil dan Pembahasan}

\subsection{Proyeksi Penduduk}

Berdasarkan data penduduk dengan metode aritmatik, Desa Siulak Gedang, hasil proyeksi jumlah penduduk dari tahun 2015 hingga pada tahun 2019 rata-rata terjadi peningkatan penduduk, sehingga perhitungan dengan metode aritmatik didapat standar deviasi, nilai $\mathrm{S}$ sebesar 1,581, dan korelasi, nilai R sebesar 0,999.

Hasil analisis perhitungan dengan menggunakan metode geometrik, didapat jumlah penduduk Desa Siulak Gedang dengan nilai standar deviasi pada metode geometrik standar deviasi, nilai S sebesar 0,00018, dan korelasi, nilai R sebesar 0,99959.

Adapun, metode proyeksi eksponensial untuk penduduk Kecamatan Pasar Kota Jambi, didapatkan standar deviasi, nilai $\mathrm{S}$ sebesar 0,354 , dan korelasi, nilai $\mathrm{R}$ sebesar 0,9996 .

Tabel 1. Proyeksi Penduduk Desa Siulak Gedang

\begin{tabular}{cccccc}
\hline No & Tahun & Penduduk & \multicolumn{3}{c}{ Proyeksi penduduk } \\
\cline { 4 - 6 } & & & Aritmatika & Eksponensial & Geometri \\
\hline 1 & 2015 & 1710 & 1710 & 1710 & 1710 \\
2 & 2016 & 1718 & 1718 & 1718 & 1718 \\
3 & 2017 & 1726 & 1726 & 1726 & 1726 \\
4 & 2018 & 1735 & 1735 & 1735 & 1735 \\
5 & 2019 & 1744 & 1744 & 1744 & 1744 \\
6 & 2020 & & 1752 & 1752 & 1752 \\
7 & 2021 & & 1761 & 1761 & 1761 \\
8 & 2022 & & 1769 & 1770 & 1770 \\
9 & 2023 & & 1778 & 1778 & 1778 \\
10 & 2024 & & 1786 & 1787 & 1787 \\
11 & 2025 & & 1795 & 1796 & 1796 \\
12 & 2026 & & 1803 & 1805 & 1805 \\
13 & 2027 & & 1812 & 1814 & 1813 \\
14 & 2028 & & 1820 & 1823 & 1822 \\
15 & 2029 & & 1829 & 1832 & 1831 \\
\hline
\end{tabular}

\subsection{Debit Air Limbah}

Perhitungan debit atau kuantitas air limbah sebagai berikut:

$\mathrm{Q}$ air bersih total = jumlah jiwa $\mathrm{x} \mathrm{Q}$ air domestik

$=1832$ jiwa $\times 80$ liter/orang/hari

$=146560$ liter $/$ hari

$=146,56 \mathrm{~m}^{3} /$ hari

$=0,00169 \mathrm{~m}^{3} /$ detik

$=1,696$ liter $/$ detik

$\mathrm{Q}$ air buangan total $=80 \% \times \mathrm{Q}$ air bersih total

$=80 \% \times 146560$ liter $/$ hari

$=117248$ liter $/$ hari

$=117,248 \mathrm{~m}^{3} /$ hari

$=0,00136 \mathrm{~m}^{3} /$ detik

$=1,357$ liter/detik

Debit air buangan yang telah diperoleh diatas merupakan debit rata-rata (average). Selanjutnya dilakukan perhitungan fluktuasi air buangan sebagai berikut:

Luas $=34,1$ ha

Jumlah penduduk terlayani $=1832$ jiwa

Qaverage $=\mathrm{Q}$ domestik

$$
\begin{aligned}
& =117248 \text { liter/hari } \\
& =117,248 \mathrm{~m}^{3} / \text { hari } \\
& =0,00136 \mathrm{~m}^{3} / \text { detik } \\
& =1,357 \text { liter/detik }
\end{aligned}
$$

Faktor puncak merupakan rasio antara debit puncak dengan debit rata-rata. Menurut Fair dan Geyer, 1954.

fpeak $=\left(18+\mathrm{p}^{0.5}\right) /\left(4+\mathrm{p}^{0.5}\right)$

fpeak $=\left(18+1832^{0.5}\right) /\left(4+1832^{0.5}\right)$ 
Fajar Arsyadani,' Monik Kasman dan Ira Galih Prabasari, Perencanaan Instalasi Pengolahan Air Limbah Desa Siulak Gedang Kecamatan Siulak Kabupaten Kerinci

Berdasarkan perhitungan didapatkan, factor peak $=1.2$

$$
\begin{aligned}
\mathrm{Q} \text { peak } & =\mathrm{Q} \text { ave } \mathrm{x} \mathrm{fp} \\
& =1832 \mathrm{~m}^{3} / \text { hari } \mathrm{x} 1,2 \\
& =2198,4 \mathrm{~m}^{3} / \text { hari }
\end{aligned}
$$

Q maksimum $=1832 \mathrm{~m}^{3} /$ hari $\times 1,25$

(faktor debit harian maksimum 1,1-1,25)

$$
\begin{aligned}
& =2290 \mathrm{~m}^{3} / \text { hari } \\
& =26,5 \text { liter/detik }
\end{aligned}
$$

$$
\begin{aligned}
\text { Q minimum } & =1 / 5 \times\left(\frac{p}{1000}\right)^{0,2} \times \text { Qave } \\
& =1 / 5 \times\left(\frac{1932}{1000}\right)^{0,2} \times 117,248 \mathrm{~m}^{2} / \text { hari } \\
& =26,468 \mathrm{~m}^{2} / \text { hari } \\
& =0,306 \text { liter/detik }
\end{aligned}
$$

Data debit air buangan yang akan dihasilkan dalam perencanaan ini untuk menghitung unit-unit bangunan IPAL adalah sebagai berikut:

Qave $=0,00136 \mathrm{~m}^{3} /$ detik $=117,248 \mathrm{~m}^{3} /$ hari

Qpeak $=0,0254 \mathrm{~m}^{3} /$ detik $=2198,4 \mathrm{~m}^{3} /$ hari

$\mathrm{Qmin}=0,000283 \mathrm{~m}^{3} /$ detik $=26,468 \mathrm{~m}^{3} /$ hari

\subsection{Perhitungan Dimensi Unit IPAL}

Berdasarkan data jumlah penduduk dan debit air limbah, maka dalam perencanaan ini unit IPAL dibagi menjadi 2, terdiri dari unit bak grase trap, unit bak pengumpul, unit bak distribusi, dan unit bak ABR (Anaerobick Baffled Reactor) serta penambahan pengolahan lanjutan yaitu kolam sanitia. Layout IPAL dapat dilihat di gambar 1.

\section{Grease Trap dan Bak Kontrol}

Minyak dan lemak merupakan polutan organik didalam air limbah dimana keberadaannya dapat menghambat transfer oksigen yang dapat menghidupkan bakteri, sehingga perlu adanya pengolahan untuk minyak dan lemak.

Agar dapat menghilangkan minyak dan lemak, dilakukan dengan menggunakan bak pemisah lemak sederhana dengan sistem gravitasi. Kriteria desain untuk bak pemisak lemak sederhana, dengan waktu tinggal di dalam bak pemisak lemak umumnya berkisar antara 30-60 menit.

HRT $: \pm 30$ menit (Grease Trap)

Ketinggian : $0,3-1 \mathrm{~m}$

Qpeak $=\frac{2198,4 \mathrm{~m}^{3} \text { hari }}{2}=1099,2 \mathrm{~m}^{3} /$ hari

Volume

$$
=\underset{\text { ao menit }}{\mathrm{HRT}} \mathrm{x} \mathrm{Q}
$$$$
=\frac{\text { a0 menit }}{60 \text { menit } \times 24 \text { jam }} \text { hari } \times 1099,2 \mathrm{~m}^{3} / \text { hari }=
$$

$$
22,9 \mathrm{~m}^{3}
$$

Tinggi

$$
=1 \mathrm{~m} \text { (rencana) }
$$

A

$$
=22,9 \mathrm{~m}^{3} / 1 \mathrm{~m}=22,9 \mathrm{~m}^{2}
$$

Panjang

$$
=\left(22,9 \mathrm{~m}^{2} / 2\right)^{0,5}=3,38 \mathrm{~m} \approx 3 \mathrm{~m}
$$

Check HRT

$$
=22,9 \mathrm{~m}^{2} / 3 \mathrm{~m}=7,63 \mathrm{~m} \approx 7,6 \mathrm{~m}
$$

$=\mathrm{T}=\frac{\mathrm{am} \times \mathrm{m} \mathrm{m} \times 1 \mathrm{~m}}{1099,2 \mathrm{~m}^{3} \text { /hari }} \times 60$ menit $\times 24$ jom

$=29,87$ menit

$=30$ menit (memenuhi kriteria)

Perhitungan diatas untuk 1 unit bak grase trap, berdasarkan data debit yang telah dihitung maka unit yang akan digunakan sebanyak 2 grase trap.

\section{Bak Pengumpul}

IPAL yang direncanakan untuk pengolahan air limbah domestik terdiri dari unit bak pengumpul yang diletakkan sebelum masuk IPAL. Bak Pengumpul pada perencanaan ini akan menerima air limbah domestik secara langsung dari grase trap dan dari kamar mandi, serta limpasan septik tank, dengan tujuan membantu mengatur beban masuk menuju IPAL. Bak pengumpul berfungsi sebagai penampung sementara air limbah domestik, sebelum dipompa menuju bangunan selanjutnya.

Waktu detensi di bak pengumpul ini relatif singkat. Beberapa hal yang harus diperhatikan yaitu dimensi pipa sewer yang masuk ke bak pengumpul dan dimensi pompa yang digunakan. Berikut perhitungan dimensi bak Pengumpul:

Direncanakan:

Bak berbentuk segi empat

Jumlah Bak : 2

Waktu Detensi/ td (<10 menit) $: 5$ menit $=300$ detik

Diameter pipa sewer terakhir $200 \mathrm{~mm}$

Kedalaman pipa sewer terakhir : 1,3 m

Tinggi sumur $\quad: 1 \mathrm{~m}$

P:L $: 1: 1$

Maka, Volume $(\mathrm{V})=\mathrm{Q}_{\text {peak }} \mathrm{X} \mathrm{Td}$

$$
\begin{aligned}
& =\left(0,0127 \mathrm{~m}^{3} / \text { detik } \times 60\right) \times 5 \text { menit } \\
& =3,8 \mathrm{~m}^{3}
\end{aligned}
$$

Asurface (As) $\quad=\frac{V}{1}=\frac{3,8}{1}=3,8 \mathrm{~m}^{2}$

Panjang $=$ Lebar $=\sqrt{\text { AS }}=\sqrt{3}, 8=2 \mathrm{~m}$

Cek Td $=V / Q_{\text {peak }}=3,8 \mathrm{~m}^{3} /\left(0,0127 \mathrm{~m}^{3} /\right.$ detik $)$

$=300$ detik (memenuhi kriteria)

$\mathrm{H}$ air saat $\mathrm{Q}_{\text {ave }}=\mathrm{Q}_{\text {ave }} \mathrm{x} \mathrm{Td} / \mathrm{A}$

$=0,000679 \mathrm{~m}^{3} /$ detik $\times\left(60 \times 5\right.$ menit $\left./ 3,8 \mathrm{~m}^{2}\right)$

$=0,05 \mathrm{~m}$

$\mathrm{H}$ air saat $\mathrm{Q}_{\min }=\mathrm{Q}_{\min } \mathrm{x} \mathrm{Td} / \mathrm{A}$

$=0,000153 \mathrm{~m}^{3} / \operatorname{detik} \times\left(60 \times 5\right.$ menit $\left./ 3,8 \mathrm{~m}^{2}\right)$

$=0,012 \mathrm{~m}$

$\mathrm{H}$ air saat $\mathrm{Q}_{\text {peak }}=\mathrm{Q}_{\text {peak }} \times \mathrm{Td} / \mathrm{A}$

$=0,0127 \mathrm{~m}^{3} / \operatorname{det}$ ik $\times\left(60 \times 5\right.$ menit $\left./ 3,8 \mathrm{~m}^{2}\right)$

$=1 \mathrm{~m}$

Sehingga, diperoleh dimensi sebagai berikut:
Panjang (P)
Lebar (1)
$=2 \mathrm{~m}$
Kedalaman $(\mathrm{H})$
Free board $(\mathrm{Fb})$
$=2 \mathrm{~m}$
$=1 \mathrm{~m}$
Total H

$$
\begin{aligned}
& =0,1 \mathrm{~m} \\
& =1+0,1=1,1 \mathrm{~m}
\end{aligned}
$$

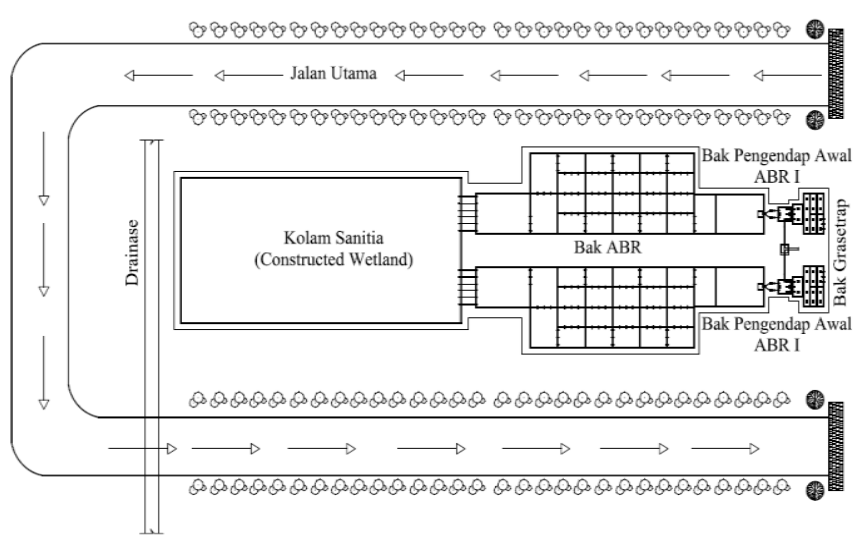

Gambar 1. Layout IPAL 


\section{Bar Screen}

Bar Screen digunakan untuk menyaring air limbah dan padatan yang masuk serta sampah dari pipa sewer grase trap sebelum masuk ke sumur pengumpul.

Direncanakan:

a. Pembersihan bar screen dilakukan secara manual;

b. Kemiringan batang secara vertical sebesar $65^{\circ}$;

c. Jarak antar batang sebesar $50 \mathrm{~mm}$;

d. Lebar batang sebesar $15 \mathrm{~mm}$

Lebar total screen = lebar sumur pengumpul $=2 \mathrm{~m}$

Sehingga jumlah batang yang diperlukan :

Lebar total $\quad=($ jarak antar batang $\mathrm{x} \mathrm{n})+($ lebar batang $\mathrm{x}$ $(\mathrm{n}-1))$

$2 \mathrm{~m}=(0,05 \times \mathrm{n})+(0,15 \times(\mathrm{n}-1))$

$2 \mathrm{~m}=0,05 \mathrm{n}+0,15 \mathrm{n}-0,15$

$2,15 \mathrm{~m}=0,2 \mathrm{n}$

$\mathrm{n}=10,75 \approx 11$ batang

\section{Pompa}

Penggunaan pompa dalam perencanaan ini diletakkan pada bak pengumpul. Fungsi pompa ini adalah untuk mengalirkan air limbah domestik dari bak pengumpul menuju unit IPAL. Pompa yang digunakan adalah pompa tipe submersible non clogging.

Direncanakan :

$\mathrm{v}$ asumsi $=1 \mathrm{~m} / \mathrm{s}$

pompa digunakan untuk 2 unit bak pengumpul

$\mathrm{Q}_{\text {peak }}=0,0254 \mathrm{~m}^{3} /$ detik $=2198,4 \mathrm{~m}^{3} /$ hari $=0,0127 \mathrm{~m}^{3} /$ detik $=1099,2 \mathrm{~m}^{3} /$ hari

$\mathrm{Q}_{\text {ave }}=0,0132 \mathrm{~m}^{3} /$ detik $=117,248 \mathrm{~m}^{3} /$ hari

$\mathrm{Q}_{\text {ave }}=0,000679 \mathrm{~m}^{3} /$ detik $=58,624 \mathrm{~m}^{3} /$ hari

Head Statik $(\mathrm{Hs})=1 \mathrm{~m}$

Panjang pipa discharge $(\mathrm{L})=7 \mathrm{~m}$

Kecepatan rencana pengaliran air limbah pada pipa adalah 1 $\mathrm{m} /$ det.

A pipa $=\frac{Q \text { peak }}{\mathrm{V}}=\frac{0,0127 \mathrm{~m}^{3} \text { fletik }}{1}=0,0127 \mathrm{~m}^{2}$

Maka, diameter discharge pada pompa;

$\mathrm{D}=\sqrt{\frac{4 \mathrm{xA}}{\mathrm{a}_{\Perp} 14}}=\sqrt{\frac{4 \mathrm{x}, 0,0127}{3,14}}=0,13 \mathrm{~m}$

A pipa cek $=\frac{1}{4} \times \pi \times D^{2}=\frac{1}{4} \times 3,14 \times 0,13^{2}$

$$
=0,0133 \mathrm{~m}^{2}
$$

Diperoleh kecepatan aliran pompa;

v cek $=\frac{Q}{A}=\frac{0,0127 \mathrm{~m}^{3} \text { detik }}{0,0127 \mathrm{~m}^{3} \text { detik }}=1 \mathrm{~m} / \mathrm{s}$

1. Head Mayor adalah berbagai kerugian head di sepanjang pipa, (Tahara, 2000).

$$
\begin{aligned}
& \text { hfdischarge }=\left[\frac{\mathrm{Q}}{0,2785 \times \mathrm{L}_{\mathrm{x}} \mathrm{D}^{2}}\right]^{1,85} \times 0,5 \\
& \text { hfdischarge }=\left[\frac{0,0127 \mathrm{~m}^{3} / \text { detik }}{0,2785 \mathrm{~m}(10)(0,13)^{2}}\right]^{1,85} \times 0,5 \\
& \text { hfdischarge }=0,07 \mathrm{~m}
\end{aligned}
$$

2. Head minor adalah berbagai kerugian head akibat katup, belokan, sambungan, dan lain-lain, (Tahara, 2000). Head minor yang terjadi adalah akibat belokan 900, akibat gate valve, check valve, percabangan, dan pembesaran penampang pipa.

Head minor akibat belokan $90^{\circ}$

Head minor akibat belokan $90^{\circ}$ terjadi sebanyak sekali, nilai k pada belokan $90^{\circ}$ yaitu 0,25 (Ningrum, 2008)

$h f=n\left[k_{\frac{v^{2}}{v^{2}}}^{\frac{v^{2}}{2}}\right]$ $h f=1\left[0,25 \frac{1^{2}}{2[9,91)}\right]$

$h f=0,01 \mathrm{~m}$

Hf kecepatan $=\frac{\mathrm{V}^{2}}{2 \mathrm{~g}}=\frac{\mathrm{I}^{2}}{2 \times 9.91}=0,05 \mathrm{~m}$

$\mathrm{H}$ sisa tekan diasumsikan $0,5 \mathrm{~m}$

Perhitungan Head Total Pompa

$H=1+0,07+0,01+0,05+0,5$

$\mathrm{H}=3,1 \mathrm{~m}$

\section{Bak Distribusi}

Bak Distribusi atau bak pembagi berfungsi sebagai bak penampung air yang akan didistribusikan menuju bangunan pengolahan selanjutnya dengan tujuan aliran yang masuk didapatkan secara merata atau laminer. Sama halnya dengan bak pengumpul, kriteria desain pada waktu detensi dalam bak pembagi relatif singkat dan lebih cepat dari bak pengumpul karena tidak berfungsi sebagai penampung sehingga aliran yang masuk harus sesegera mungkin untuk dialirkan kembali kedalam bangunan selanjutnya. Desain bak distribusi, salah satu hal yang harus diperhatikan yaitu dimensi yang didisain tidak terlalu besar agar tidak terjadi pengendapan sedimen dan tidak menggunakan pompa pada zona outlet untuk efisiensi pengaliran. Pada perencanaan ini, bak distribusi digunakan pada IPAL karena lebih dari satu bangunan ABR. Perhitungan bak distribusi:

Direncanakan 2 bak distribusi

Waktu detensi (td) $<3$ menit untuk menghindari terjadinya pengendapan lumpur

$$
\begin{aligned}
& \text { Td } \quad=1 \text { menit }=60 \text { detik } \\
& \text { Qpeak } \quad=0,0254 \mathrm{~m}^{3} / \text { detik }=2198,4 \mathrm{~m}^{3} / \text { hari } \\
& \text { Qpeak } \quad=0,0127 \mathrm{~m}^{3} / \text { detik }=1099,2 \mathrm{~m}^{3} / \text { hari }
\end{aligned}
$$

Perhitungan:

Volume Bak Distribusi= Qpeak $\mathrm{x}$ Td

$=0,0127 \mathrm{~m}^{3} /$ detik $\times 60$ detik $=0,726 \mathrm{~m}^{3}$

Asurface Bak Distribusi $=\frac{\text { Volume Bak Pengumpul }}{\text { Kedalaman Bak Pengumpul }}$

Rasio P: $\mathrm{L}=1: 1=\sqrt{0,726 \mathrm{~m}^{2}}$

$$
=\frac{0,726 \mathrm{~m}^{3}}{1 \mathrm{~m}}=0,726 \mathrm{~m}^{2}
$$

Panjang bak distribusi $=0,85 \mathrm{~m}$

Lebar bak distribusi $=0,85 \mathrm{~m}$

Volume bak distribusi

$=\mathrm{p} \times 1 \times \mathrm{h}=0,85 \mathrm{~m} \times 0,85 \mathrm{~m} \times 1 \mathrm{~m}$

$=0,723 \mathrm{~m}^{3}$

$$
\begin{aligned}
\text { Cek td }= & \frac{\text { wolume }}{\text { debit peak }}=\frac{0,723 \mathrm{~m}^{3}}{0,0127 \mathrm{~m}^{3} / \text { detik }} \\
& =56,92 \text { detik } \approx 60 \text { detik } \\
& =\text { (memenuhi kriteria) }
\end{aligned}
$$

Kriteria dimensi Bak Distribusi:

$\begin{array}{ll}\text { Luas Area } & =0,723 \mathrm{~m}^{2} \\ \text { Panjang } & =0,85 \mathrm{~m} \\ \text { Lebar } & =0,85 \mathrm{~m} \\ \text { Kedalaman } & =1+0,2=1,2 \mathrm{~m}\end{array}$

\section{Unit ABR}

Pengolahan air limbah domestik yang hanya menggunakan proses anaerob maka hasil olahan hanya dapat menurunkan konsentrasi polutan minyak atau lemak, organik (BOD, COD), total padatan tersuspensi (TSS) dan amoniak 
Fajar Arsyadani,' Monik Kasman dan Ira Galih Prabasari, Perencanaan Instalasi Pengolahan Air Limbah Desa Siulak Gedang Kecamatan Siulak Kabupaten Kerinci

$\left(\mathrm{NH}_{3}\right)$. Sedangkan untuk total coliform tidak bisa turun. Jika prosesnya anaerob-aerob, maka dapat menurunkan konsentrasi polutan minyak atau lemak, organik, amoniak, TSS, dan total coliform.

Debit Air Limbah

Dari parameter air limbah yang diperoleh maka dapat dilakukan perhitungan. Contoh perhitungan akan dilakukan pada:

td = direncanakan 3 jam (kriteria 2-6 jam) Selanjutnya dari td yang telah direncanakan selama 3 jam, maka dapat diperoleh \% removal TSS dan BOD melalui grafik berikut:

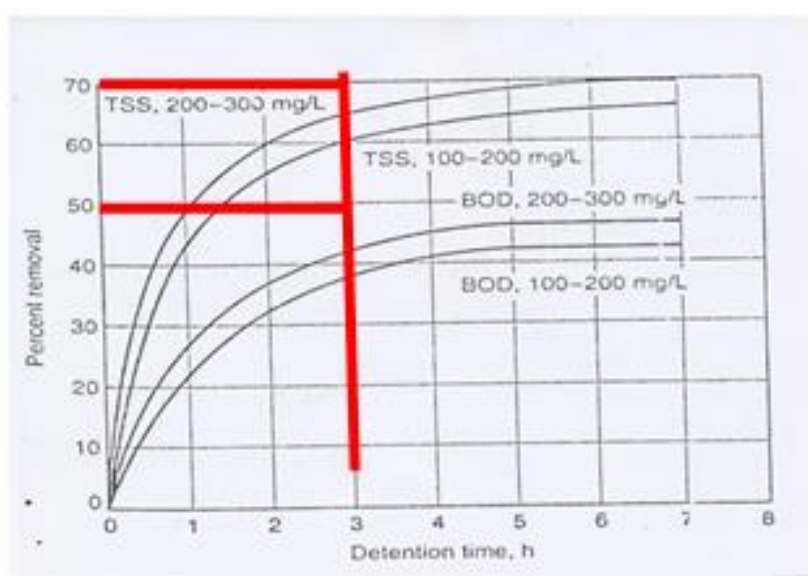

Gambar 2. Grafik Hubungan Antara td dan \%

Removal TSS \& BOD (Rosidi,2017)

$$
\begin{aligned}
& \% \text { Removal TSS }=65 \% \\
& \% \text { Removal BOD }=42 \% \\
& \% \text { Removal COD }=42 \%
\end{aligned}
$$

Debit Air Limbah

Qave $=0,00136 \mathrm{~m}^{3} /$ detik $=\left(117,248 \mathrm{~m}^{3} /\right.$ hari $\left./ 2\right)$

Qave $=0,000679 \mathrm{~m}^{3} /$ detik $=58,624 \mathrm{~m}^{3} /$ hari

Qpeak $=0,0254 \mathrm{~m}^{3} /$ detik $=\left(2198,4 \mathrm{~m}^{3} / \mathrm{hari} / 2\right)$

Qpeak $=0,0127 \mathrm{~m}^{3} /$ detik $=1099,2 \mathrm{~m}^{3} /$ hari

Qmin $=0,000153 \mathrm{~m}^{3} /$ detik $=\left(26,468 \mathrm{~m}^{3} /\right.$ hari $\left./ 2\right)$

Qmin $=0,000153 \mathrm{~m}^{3} /$ detik $=26,468 \mathrm{~m}^{3} /$ hari

\section{Effluent BOD, TSS, COD}

$\mathrm{TSS}=(100-65) \% \times 90 \mathrm{mg} / \mathrm{L}=31,5 \mathrm{mg} / \mathrm{L}$

$\mathrm{COD}=(100-42) \% \times 310 \mathrm{mg} / \mathrm{L}=179,8 \mathrm{mg} / \mathrm{L}$

$\mathrm{BOD}=(100-42) \% \times 300 \mathrm{mg} / \mathrm{L}=174 \mathrm{mg} / \mathrm{L}$

Massa Lumpur BOD, TSS, COD

Massa TSS = removal TSS x kadar TSS x Q limbah $=\frac{65 \% 6 \times 31,5 \mathrm{mg} / 1 \times 1099200 \text { 1forg hari }}{1,000.000}$
$=22,51 \mathrm{~kg} / \mathrm{hari}$

Massa COD = removal COD x kadar COD x Q limbah

$$
\begin{aligned}
& =\frac{4236 \times 179.8 \mathrm{mg} / 1 \times 1099200 \text { 1/forg hari }}{1.000 .000} \\
& =83 \mathrm{~kg} / \mathrm{hari}^{2}
\end{aligned}
$$

Massa BOD = removal BOD x kadar BOD x Q limbah

$$
\begin{aligned}
& =\frac{4286 \times 174 \mathrm{mg} / 1 \times 1099200 \mathrm{l} \text { forg hari }}{1.000 .000} \\
& =80,32 \mathrm{~kg} / \mathrm{hari}
\end{aligned}
$$

Produksi Lumpur selama 2 tahun (Berdasarkan SNI)

Massa lumpur dihasilkan

$=$ Total Lumpur SS x durasi pengurasan

$=22,51 \mathrm{Kg} /$ hari $\times 2$ tahun $\times 365$ hari

$=16432 \mathrm{Kg} / 2$ tahun

Stabilisasi lumpur setelah 2 tahun, dapat diketahui persentase volume lumpur dari grafik hubungan antara pengurangan volume lumpur pada bulan tertentu yaitu sebesar $62 \%$.

Stabilisasi lumpur 2 tahun $=62 \% \mathrm{x}$ produksi lumpur $=62 \% \times 16.432 \mathrm{Kg} / \mathrm{tahun}$

Densitas Lumpur

Konsentrasi lumpur $\quad=5 \%$.

Densitas lumpur $\quad=2,65 \mathrm{~kg} / \mathrm{L}$;

Konsentrasi air $\quad=95 \%$

Densitas air [596 x plumpur $)+[9596 \mathrm{x}$ pair $]$

$$
=1 \mathrm{~kg} / \mathrm{L}
$$

10028

$=\frac{(596 \times 2,65)+(9596 \times 1)}{900}$

$=1.09 \mathrm{~kg} / \mathrm{L}$

Volume lumpur pada settling zone

Volume lumpur

= stabilisasi lumpur 1 tahun / $\rho$ Lumpur

$=10188 \mathrm{~kg} / 1,09 \mathrm{~kg} / \mathrm{L}$

$=9347 \mathrm{~L}$

$=9,347 \mathrm{~m}^{3}$

reduction of sludge volume during storage

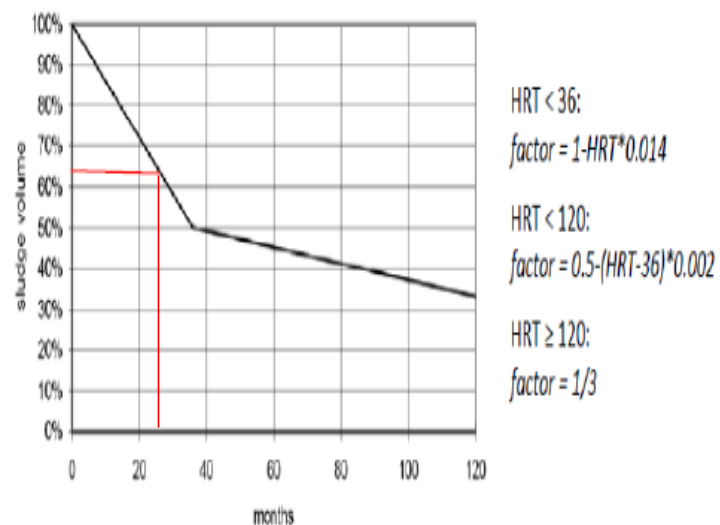

Gambar 3. Grafik Hubungan Antara Pengurangan Volume Lumpur terhadap Waktu (Rosidi,2017)

Menentukan rencana kedalaman air di dalam ruang $\mathrm{ABR}$ kompartemen 1

Kemanpuan gali $\quad=2,5 \mathrm{~m}$

Free board $\quad=0,2 \mathrm{~m}$

Tebal dinding bawah $\quad=20 \mathrm{~cm}$

Tebal dinding plat $\quad=15 \mathrm{~cm}$

Ketinggian ABR rencana $(\mathrm{H})=2 \mathrm{~m}$

Dimensi Ruang Lumpur dan Kompartemen 1

Kedalaman ABR (h) $\quad=2 \mathrm{~m}$

$\mathrm{h}$ ruang lumpur, $\mathrm{d}=1 / 3 \times \mathrm{h} \mathrm{ABR}$

$=\frac{1}{3} \times 2 \mathrm{~m}$

$=0,67 \mathrm{~m}$ 
Fajar Arsyadani,' Monik Kasman dan Ira Galih Prabasari, Perencanaan Instalasi Pengolahan Air Limbah Desa Siulak Gedang Kecamatan Siulak Kabupaten Kerinci

Luas ruang lumpur $=$ Volume lumpur/h ruang lumpur

$$
\begin{aligned}
& =9,347 \mathrm{~m}^{3} / 0,67 \mathrm{~m} \\
& =13,95 \mathrm{~m}^{2}
\end{aligned}
$$

Volume kompartemen I = Qpeak x td

$=1099,2 \mathrm{~m}^{3} /$ hari $\times 3$ jam $\times 1 / 24$ hari/jam

$=137,4 \mathrm{~m}^{3}$

Luas kompartemen I = Volume / h kompartemen I

$=($ Qpeak x td $) / \mathrm{h}$ kompartemen I

$=\frac{1099,2 \mathrm{~m}^{3} / \text { hari } \times \text { a jam } \mathrm{xi} / 24 \text { harifjam }}{2}$

$=\frac{137,4 \mathrm{~m}^{3}}{2 \mathrm{~m}}=68.7 \mathrm{~m}^{2}$

Asumsi lebar $=5,86 \mathrm{~m} \approx 6 \mathrm{~m}$

Panjang ruang lumpur $=$ Luas ruang lumpur $/$ lebar

$=13,95 \mathrm{~m}^{2} / 6 \mathrm{~m}=3,49 \mathrm{~m}$

Panjang kompartemen I

= Luas kompartemen I / lebar

$=68,7 \mathrm{~m}^{2} / 6 \mathrm{~m}$

$=11,45 \mathrm{~m}$

Dari hasil perhitungan dimensi luas ruang lumpur lebih besar dibandingkan dengan ruang kompartemen I sehingga berpengaruh terhadap panjang masing-masing bangunan. Panjang yang digunakan adalah yang memiliki nilai terbesar yaitu $7 \mathrm{~m}$ karena untuk titik teraman bangunan. Sehingga kedalaman pada bangunan dapat dihitung sebagai berikut:

$$
\begin{aligned}
\text { Kedalaman }(\mathrm{h}) & =\frac{\text { Volume Bak Pengendap }}{\text { Panjang } \times \text { Lebary }} \\
& =\frac{137,4 \mathrm{~m}^{3}}{11,45 \mathrm{mx} 6 \mathrm{~m}} \\
& =2 \mathrm{~m} \\
& \text { (memenuhi kriteria desain } \leq 4 \mathrm{~m})
\end{aligned}
$$

Dimensi Kompartemen I

Panjang total + dinding plat

$=11,45 \mathrm{~m}+(2 \times 0,15) \mathrm{m}=11,75 \mathrm{~m}$

Lebar total + dinding plat

$=6 \mathrm{~m}+(2 \times 0,15) \mathrm{m}=6,3 \mathrm{~m}$

Kedalaman total

$=$ Kedalaman + freeboard + dinding plat bawah

$=2 \mathrm{~m}+0,2 \mathrm{~m}+0,2 \mathrm{~m}$

$=2,4 \mathrm{~m}$

Dimensi Kompartemen 2

$\mathrm{Q}$ influent $=\mathrm{Q}$ effluent kompartemen 1

$$
\begin{aligned}
& =1099,2 \mathrm{~m}^{3} / \text { hari } \\
& =0,0127 \mathrm{~m}^{3} / \text { detik }
\end{aligned}
$$

Rentang HLR $=(16,8-38,4) \mathrm{m}^{3} / \mathrm{m}^{2}$.hari

HLR rencana $=20 \mathrm{~m}^{3} / \mathrm{m}^{2}$.hari (agar luas permukaan tidak terlalu besar, sehingga dimensi tidak terlalu besar)

$$
\begin{aligned}
\text { HRT rencana } & =20 \text { jam } \\
\text { Asurface total } & =\frac{\text { Qinfluent fumiah ABR }}{H L R \text { rencana }} \\
& =1099,2 \mathrm{~m}^{3} / \text { hari } / 20 \mathrm{~m}^{3} / \mathrm{m}^{2} \text {.hari } \\
& =54,96 \mathrm{~m}^{2} \sim 55 \mathrm{~m}^{2}
\end{aligned}
$$

Tinggi total ABR

$=$ HLR rencana $\mathrm{x}(\mathrm{HRT}$ rencana/24)
$=20 \mathrm{~m}^{3} / \mathrm{m}^{2}$.hari $\mathrm{x}(20 / 24)$

$=16,67 \mathrm{~m}$

Jumlah kompartemen $=\frac{\text { tinggi total } A B R \text { tinggi }}{\text { tingg kompartemen } 1}$

$$
\begin{aligned}
& =16,67 \mathrm{~m} / 2,4 \mathrm{~m} \\
& =6,945 \text { unit } \approx 7 \text { unit }
\end{aligned}
$$

Dimensi ABR $\rightarrow$

lebar kompartemen $=6,3 \mathrm{~m}$

Panjang kompartemen $=$ Asurface total $/$ lebar

$$
\begin{aligned}
& =55 \mathrm{~m}^{2} / 6,3 \mathrm{~m} \\
& =8,7 \mathrm{~m} \sim 9 \mathrm{~m}
\end{aligned}
$$

Cek Asurface total $=$ panjang $\mathrm{x}$ lebar

$$
\begin{aligned}
& =9 \mathrm{~m} \times 6,3 \mathrm{~m} \\
& =56,7 \mathrm{~m}^{2}
\end{aligned}
$$

Cek HRT $\quad=\frac{\text { As cek } x t \text { kompartemenn } 1 \times \text { jumlah kompartemen }}{Q}$

$$
=\frac{56,7 \mathrm{~m} \times 2,4 \mathrm{~m} \times 7 \text { unit }}{1099,2 \mathrm{~m}^{3} \text { /hari }}
$$$$
=20,79 \text { jam }
$$

Cek Vup = Qpeak / Asurface

$$
=1099,2 \mathrm{~m}^{3} / \text { hari } / 56,7 \mathrm{~m}^{2}
$$

$=19,39 \mathrm{~m}^{3} / \mathrm{m}^{2}$.hari

$=0,81 \mathrm{~m} / \mathrm{jam}<2 \mathrm{~m} / \mathrm{jam}$

(memenuhi kriteria)

Cek OLR $=\frac{\text { massa COD effluent }}{2}$

$$
\begin{aligned}
& \text { jumlah kompartemen } x \text { lebar } x \text { tinggi } \\
& =\frac{\text { 82. } \mathrm{kg} / \mathrm{hari}}{7 \text { kompartemen } \mathrm{x} 6,3 \mathrm{~m} \times 2,4 \mathrm{~m}} \\
& =0,78 \mathrm{~kg} \mathrm{COD} / \mathrm{m}^{3} \cdot \text { hari }<3 \mathrm{~kg} \mathrm{COD} / \mathrm{m}^{3} \text {.hari } \\
& \text { (memenuhi kriteria) }
\end{aligned}
$$

Free board $=0,2 \mathrm{~m}$

Tebal dinding $=0,15 \mathrm{~m}$

Penentuan \% removal BOD

Faktor grafik BOD removal effect of organic overloading

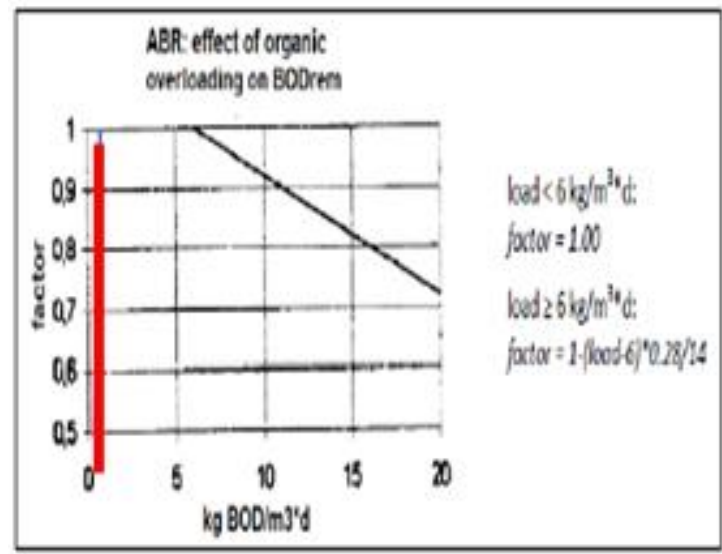

Gambar 4. Grafik Faktor Penyisihan BOD Terhadap Organic Overloading (Rosidi,2017)

$$
\begin{aligned}
& \mathrm{OLR}=\frac{\mathrm{Q} \times[\mathrm{BOD} \mathrm{in}]}{\text { Wol }}=\frac{\mathrm{Q} \times[\mathrm{BOD} \text { in }]}{\mathrm{p} \times 1 \times \mathrm{h} \times \text { jumlah kompartemen }} \\
& =1099.2 \mathrm{~m}^{3} / \mathrm{hari} \times 174 \mathrm{mg} / \mathrm{L} \\
& =0,0003 \mathrm{~kg} \mathrm{BOD} / \mathrm{m}^{3} \cdot \text { hari }
\end{aligned}
$$

Faktor BOD removal $=1$

Panjang total ABR 
Fajar Arsyadani,' Monik Kasman dan Ira Galih Prabasari, Perencanaan Instalasi Pengolahan Air Limbah Desa Siulak Gedang Kecamatan Siulak Kabupaten Kerinci

$=($ panjang per kompartemen $\mathrm{x}$ jumlah kompartemen $)+$ (tebal dinding $\mathrm{x}$ jumlah kompartemen)

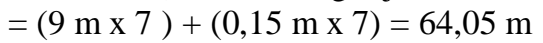

Perhitungan Produksi Lumpur ABR

Diketahui :

$\mathrm{BOD}=174 \mathrm{mg} / \mathrm{l}=22,51 \mathrm{~kg} / \mathrm{hari}$

$\mathrm{COD}=179,8 \mathrm{mg} / \mathrm{l}=83 \mathrm{~kg} / \mathrm{hari}$

$\mathrm{TSS}=31,5 \mathrm{mg} / \mathrm{l}=45 \mathrm{~kg} / \mathrm{hari}$

Faktor dari grafik BOD removal according to strength

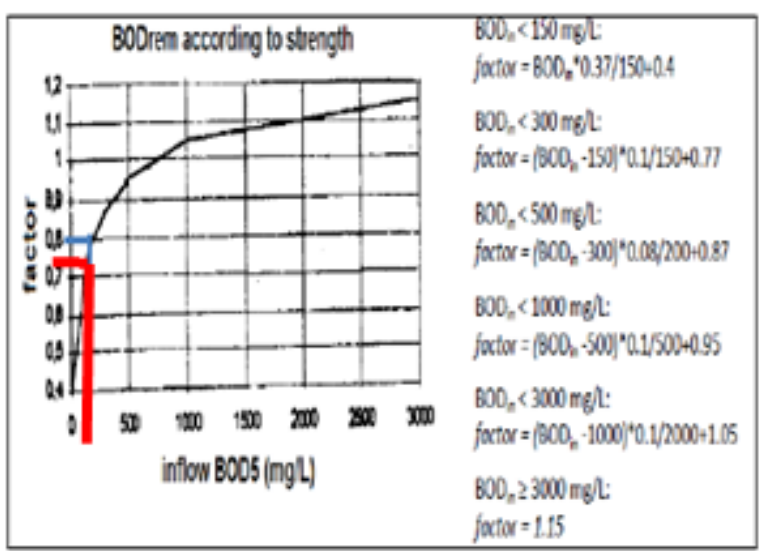

Gambar 5. Grafik Faktor Penyisihan BOD Terhadap Konsentrasi BOD (Rosidi,2017)

Konsentrasi Influent BOD $=174 \mathrm{mg} / \mathrm{L}$

Faktor BOD removal $=0,82$

Faktor dari grafik $B O D$ removal relative to temperature

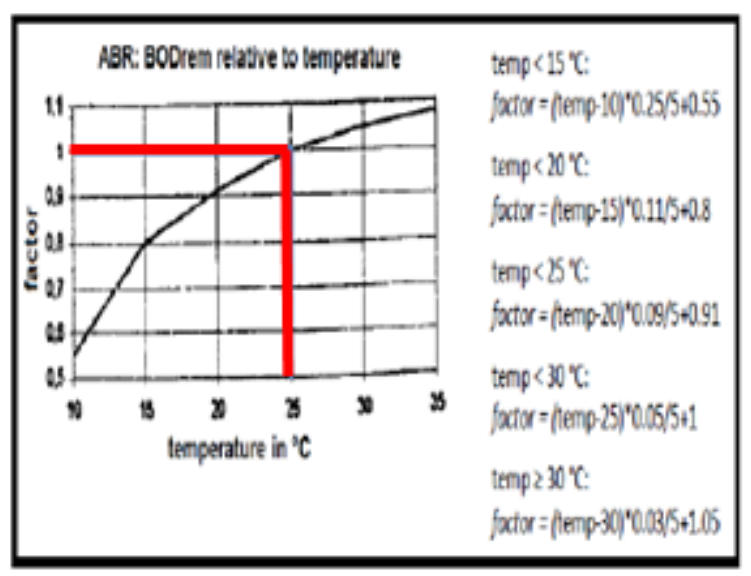

Gambar 6. Grafik Faktor Penyisihan BOD Terhadap Temperatur (Sasse, 2009)

Asumsi temperatur air limbah $25^{\circ} \mathrm{C}$

Faktor temperatur $=1$

Faktor dari grafik $B O D$ removal relative to number upflow chamber

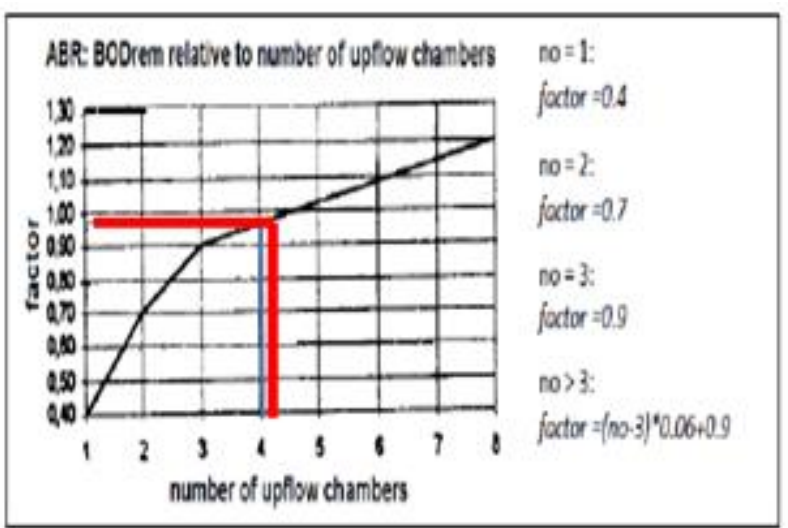

Gambar 7. Grafik Faktor Penyisihan BOD Terhadap Jumlah Kompartemen (Sasse,2009)

Total kompartemen ABR $=7$ kompartemen Faktor $=1,19$

$\underline{\text { Faktor dari BOD removal relative to } \mathrm{HRT}}$

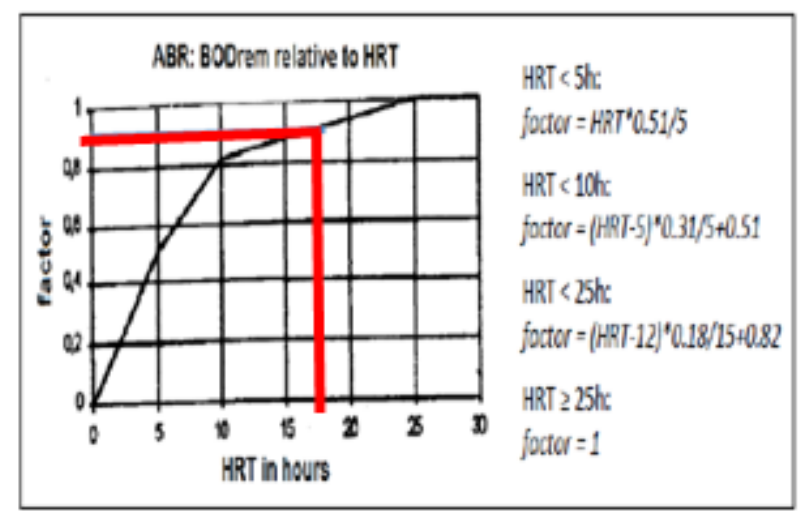

Gambar 8. Grafik Faktor Penyisihan BOD Terhadap HRT (Rosidi,2017)

HRT rencana $=20$ jam

Faktor $=0,91$

Removal BOD $=1 \times 0,82 \times 1 \times 1,19 \times 0,91$

$=89 \%$

Produksi Lumpur BOD

Range koefisien yield : $\gamma=0,05-1$

(yang digunakan 0,08)

Produksi lumpur

$\mathrm{Px}=\gamma \mathrm{x} \%$ removal BOD $\mathrm{x}$ konsentrasi influent $\mathrm{x}$ Qpeak

$=0,08 \times 0,73 \times 0,0003 \mathrm{Kg} / \mathrm{L} \times 1099200 \mathrm{~L} /$ hari

$=19,26 \mathrm{Kg} /$ hari

Produksi Lumpur TSS

Lumpur TSS $=($ Konsentrasi TSS - Baku mutu $) \mathrm{x}$ Qpeak

$=(31,5 \mathrm{mg} / \mathrm{L}-30 \mathrm{mg} / \mathrm{L}) \times 1099200 \mathrm{~L} / \mathrm{hari}$

$=1,65 \mathrm{Kg} / \mathrm{hari}$

Total Lumpur

Total lumpur = Lumpur BOD + Lumpur TSS

$=19,26 \mathrm{Kg} /$ hari $+1,65 \mathrm{Kg} / \mathrm{hari}$ 
Fajar Arsyadani,' Monik Kasman dan Ira Galih Prabasari, Perencanaan Instalasi Pengolahan Air Limbah Desa Siulak Gedang Kecamatan Siulak Kabupaten Kerinci

$$
=20,91 \mathrm{Kg} / \mathrm{hari}
$$

Lumpur selama 2 tahun

Massa lumpur dihasilkan $=$ Total Lumpur $\quad \mathrm{x}$ durasi pengurasan

$=20,91 \mathrm{Kg} /$ hari $\times 2$ tahun $\mathrm{x} 365$ hari

$=15.264 \mathrm{Kg} / 2$ tahun

Grafik hubungan antara pengurangan volume lumpur pada bulan tertentu selama 2 tahun atau 24 bulan maka didapat persentase removal yaitu $62 \%$

reduction al susge wiane during storage

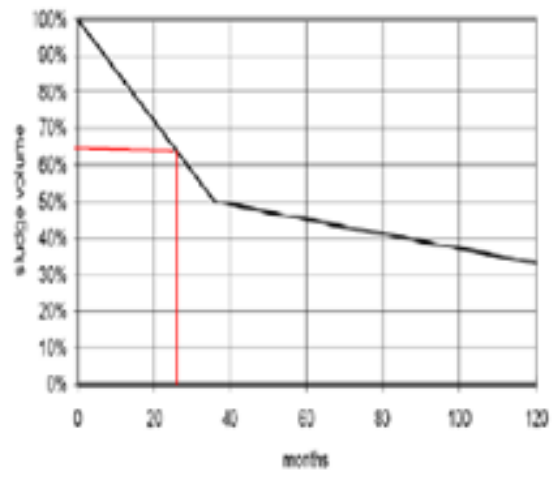

Gambar 9.Grafik Hubungan Antara Pengurangan Volume Lumpur Oleh Waktu (Rosidi,2017)

Stabilisasi lumpur 2 tahun $=62 \%$ x produksi lumpur

$=62 \% \times 15264 \mathrm{Kg} /$ tahun

$=9463,7 \mathrm{Kg} / 2$ tahun

Densitas Lumpur

Konsentrasi lumpur $=5 \%$;

Densitas lumpur $=2,65 \mathrm{~kg} / \mathrm{L}$;

Konsentrasi air $=95 \%$

densitas air $=1 \mathrm{~kg} / \mathrm{L}$

$\frac{(596 \times \text { plumpur })+(9596 \times p \text { air })}{10076}$
$\frac{(596 \times 2,65)+(9596 \times 1)}{100}=1.09 \mathrm{Kg} / \mathrm{L}$

Volume Lumpur pada $A B R$

Volume lumpur

$=$ stabilisasi lumpur 2 tahun / $\rho$ Lumpur

$=4731,85 \mathrm{~kg} / 1,09 \mathrm{~kg} / \mathrm{L}$

$=4341,15 \mathrm{~L}$

$=4,34 \mathrm{~m}^{3}$

Volume lumpur $=\mathrm{P} \times \mathrm{L} \times \mathrm{t}$

$4,34 \mathrm{~m}=8, \mathrm{~m} \times 6,3 \mathrm{~m} \times \mathrm{t}$

$\mathrm{t}$ lumpur $=0,1 \mathrm{~m}$

Kualitas Effluent ABR

Effluent BOD $=(100 \%-89 \%) \times$ Konsentrasi influent $\mathrm{BOD}=11 \% \times 174 \mathrm{mg} / \mathrm{L}=19,14 \mathrm{mg} / \mathrm{L}$ (memenuhi baku mutu)

\section{$\%$ Removal COD}

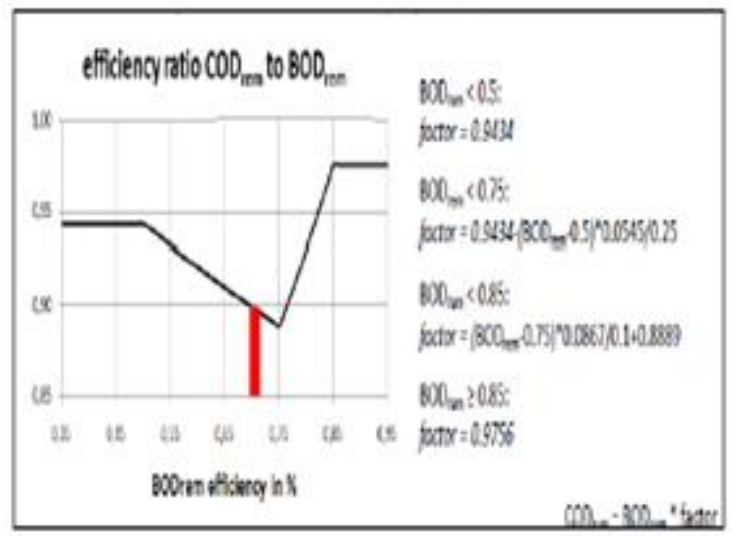

Gambar 10. Grafik Faktor Penyisihan COD Berdasarkan Penyisihan BOD (Rosidi,2017)

Removal COD $=\%$ Removal BOD $\mathrm{x}$ factor

$=0,89 \times 0,88$

$=0,78=78 \%$

Efisiensi TSS

$=\frac{\text { effluent dari kompartemen I- effluent baku mutu }}{\text { effluent dari kompartemen I }} \times 100 \%$

$=\frac{31,5 \mathrm{mg} / 1-30 \mathrm{mg} / 1}{31,5 \mathrm{mg} / 1} \times 100 \%=4,76 \%$

\section{Effluent COD}

$=(100 \%-78 \%) \times$ Konsentrasi COD influent

$=(100 \%-78 \%) \times 179,8 \mathrm{mg} / \mathrm{L}$

$=39,56 \mathrm{mg} / \mathrm{L}$ (memenuhi baku mutu)

Effluent TSS

$=(100 \%-4,76 \%) \times$ Konsentrasi TSS influent

$=(100 \%-4,76 \%) \times 31,5 \mathrm{mg} / \mathrm{L}$

$=30 \mathrm{mg} / \mathrm{L}$ (memenuhi baku mutu)

Perhitungan removal untuk minyak dan lemak dengan removal 95\% berdasarkan (Wongthanate, et al., 2004) sehingga dapat dihitung dengan persamaan sebagai berikut:

Effluent Minyak dan Lemak

$=(100 \%-95 \%) \times$ Konsentrasi

Minyak dan lemak influent $=1 \mathrm{mg} / \mathrm{L}$ (memenuhi baku mutu)

Dari hasil kualitas effluent apabila dibandingkan dengan baku mutu, BOD, COD, TSS, Minyak dan lemak telah memenuhi baku mutu limbah domestik. TSS dengan effluent sebesar $30 \mathrm{mg} / \mathrm{l}$ tidak melebihi standar bakumutu yaitu sebesar $30 \mathrm{mg} / \mathrm{l}$. Sedangkan COD dengan effluent sebesar 39,56 mg/L dibawah baku mutu sebesar $100 \mathrm{mg} / \mathrm{L}$. Selain itu BOD juga telah memenuhi baku mutu karena BOD sebesar 19,14 mg/L dibawah baku mutu air limbah domestik sebesar $30 \mathrm{mg} / \mathrm{l}$. Minyak dan lemak telah memenuhi baku mutu juga dengan 1 mg/l karena bakumutunya adalah 5 mg/l. Sedangkan Total Coliform dan amonia akan direduksi di Kolam Sanitia berupa penambahan tanaman karena pada kondisi aerob memungkinkan bakteri tersebut mati.

\section{Rencana Kolam Sanitia}

Rencana pembuatan kolam sanitia ini sebagai alternatif pengolahan air limbah dimana air limbah dapat dimanfaatkan kembali sehingga tidak mencemari air permukaan maupun air tanah, dasar dalam pembuatan kolam sanitia ini sesuai dengan 
SNI-2398-2017 tentang tata cara perencanaan tangki septik dengan pengolahan lanjutan maka direncanakan :

Waktu detensi $(\mathrm{td})=(1-1,5$ hari $)$

Debit air limbah $($ Qpeak $)=2198,4 \mathrm{~m}^{3} /$ hari

Rencana kedalam/tinggi kolam $=2 \mathrm{~m}$

Volume Kolam = 1 hari $\times 2198,4 \mathrm{~m}^{3} /$ hari

Luas kolam $=$ Volume $/$ tinggi rencana

$=2198,4 \mathrm{~m}^{3} / 2 \mathrm{~m}=1099,2 \mathrm{~m}^{2}$

Lebar kolam $=\sqrt{1099,2 / 2}=23 \mathrm{~m}$

Panjang kolam $=47,78 \mathrm{~m}$

Check td $=\frac{23 \text { mx2 mx48 } m}{2198,2 m^{3} \text { hari }}=0,99$ hari $\approx 1$ hari

1. Kolam sanita merupakan bak dari pasangan batu, dan bahan kedap lainnya diisi kerikil diameter (20-30) $\mathrm{mm}$, setinggi $80 \%$ dai tinggi bak, dan diatasnya ditanami tumbuhan kelompok hydrophyt);

2. Pipa influen dipasang dibagian bawah kolam dan pipa efluen dipasang $70 \mathrm{~mm}$ sampai $100 \mathrm{~mm}$ dibawah permukaan kerikil;

3. Air harus dijaga pada ketinggian $70 \mathrm{~mm}$ sampai dengan $100 \mathrm{~mm}$ dibawah permukaan kerikil;

4. Jenis tanaman yang dipergunakan sebaiknya 3 jenis tanaman dengan jenis perakaran yang berbeda.

\section{Kesimpulan}

Berdasarkan hasil penelitian yang telah dilakukan dapat diambil kesimpulan sebagai berikut :

1. Berdasarkan perhitungan didapatkan debit puncak pelayanan penduduk 2198,4 $\mathrm{m}^{3} /$ hari. Sehingga IPAL domestik Desa Siulak Gedang Kecamatan Siulak dibagi menjadi 2 bagian IPAL yang mengelola secara serentak, IPAL terdiri dari bak grease trap sebagai pemisah minyak dan lemak, bak pengumpul, bak distribusi, bak ABR sebagai unit proses utama air limbah dan pengolahan lanjutan dengan kolam sanitia.

2. Dimensi unit IPAL tersebut yaitu unit grease trap panjang 7,6 m, lebar $3 \mathrm{~m}$, kedalam $1 \mathrm{~m}$, unit bak pengumpul panjang $2 \mathrm{~m}$, lebar $2 \mathrm{~m}$, kedalaman $1 \mathrm{~m}$, bar screen jumlah batang 11, lebar $2 \mathrm{~m}$ dalam $1 \mathrm{~m}$, bak distribusi panjang 85 $\mathrm{cm}$, lebar $85 \mathrm{~cm}$, dan kedalaman, 1,2 m, unit bak ABR untuk unit pengendap panjang kompartemen $111,45 \mathrm{~m}$, untuk ruang lumpur 3,5 m, unit ABR kompartemen 2-7, panjang $9 \mathrm{~m}$, lebar $6 \mathrm{~m}$, kedalaman $2 \mathrm{~m}$, dan kolam sanita panjang 47,78 m, lebar $23 \mathrm{~m}$, dan kedalaman $2 \mathrm{~m}$.

\section{Daftar Pustaka}

Dama, P., Bell, J., Foxon, K. M., Brouckaert, C. J., Huang, T., Buckley, C. A., Naidoo, V., dan

Kementerian Pekerjaan Umum dan Perumahan Rakyat - Buku 3 : Pembangunan Infrastruktur Sanimas IDB (2016)

Metcalf and Eddy, (1991). Wastewater Engineering Treatment Disposal Reuse. Mc Graw Hill Comp.

Nguyen, H., Turgeon, S., dan Matte, J. (2010).The Anaerobic Baffled Reactor: A Study of The Wastewater Treatment Process Using The Anaerobic Baffled Reactor. Borchester Polytechnic Institute, USA.

Santoso. (2015). Perencanaan Pengolahan Air Limbah Domestik dengan Alternatif media Biofilter (Studi Kasus : Kejawan Gebang Kelurahan keputih
Surabaya)", Prosiding Seminar Nasional Manajemen Teknologi XXII; Surabaya, Indonesia, 24 Januari 2015

Sasse, L. (1998). Dewats: Decantralised Wastewater Treatment in Developing Countries.Borda. Delhi

SNI 8455 (2017) - Perencanaan pengolahan air limbah rumah tangga dengan sistem reaktor anaerobik bersekat (SRAB) Indonesia,

Stuckey, D. C. (2002). Pilot Scale Study of An Anaerobic Baffled Reactor for TheTreatment of Domestic Wastewater. Water Science \& Technology, 46 (9), pp. 263-270 